\title{
Effects of clown activities on patients eligible for palliative care in primary health care
}

\author{
Efeitos de atividades clown em pacientes elegíveis para cuidados paliativos na atenção primária à saúde
}

Efectos de actividades clown en pacientes elegibles para cuidados paliativos en la atención primaria de salud

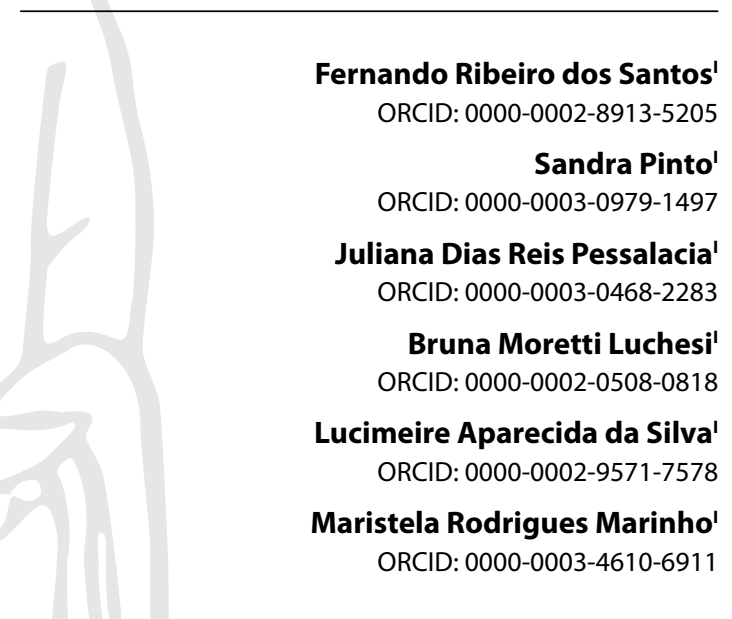

'Universidade Federal de Mato Grosso do Sul. Três Lagoas, Mato Grosso do Sul, Brazil.

How to cite this article:

Santos FR, Pinto S, Pessalacia JDR, Luchesi BM, Silva LA, Marinho MR. Effects of clown activities on patients eligible for palliative care in primary health care. Rev Bras Enferm. 2021;74(5):e20200431. https://doi.org/10.1590/0034-7167-2020-0431

Corresponding author:

Fernando Ribeiro dos Santos

E-mail: fernando.ribeiro@ufms.br

EDITOR IN CHIEF: Dulce Barbosa ASSOCIATE EDITOR: Rafael Silva

Submission: $07-07-2020$

Approval: 02-07-2021

\section{ABSTRACT}

Objective: Evaluate the effects of clown activities on quality of life, depression, stress, anxiety, aid, and social support in patients eligible for palliative care (PC) attended in Primary Health Care (PHC). Method: A quasi-experimental study, with pre-intervention and post-intervention evaluation, carried out with 16 patients eligible for early PC in PHC in a Midwestern city. Patients received 24 visits with home-based clown activities. Results: The interventions evidenced improved quality of life and social support, with significant results for the Social Activities dimension $(p=0.023)$. Increased scores for Anxiety $(p=0.007)$ and Depression $(p=0.023)$ were also observed. Conclusion: Clown activities can bring positive results for the quality of life and social support of patients eligible for PC at home. They should be encouraged to interact with family knowledge and enhance humanized care, integral and centered on human relationships in PHC. Descriptors: Palliative Care; Primary Health Care; Laughter Therapy; Quality of Life; Psychometrics.

\section{RESUMO}

Objetivo: Avaliar os efeitos de atividades clown na qualidade de vida, depressão, estresse, ansiedade, apoio e suporte social em pacientes elegíveis para cuidados paliativos (CP) atendidos na Atenção Primária à Saúde (APS). Método: Estudo quase-experimental, com avaliação pré-intervenção e pós-intervenção, realizado com 16 pacientes elegíveis para CP precoces na APS em um município do Centro-Oeste. Os pacientes receberam 24 visitas com atividades clown domiciliares. Resultados: As intervenções evidenciaram melhora da qualidade de vida e do suporte social, com resultados significativos para a dimensão Atividades sociais $(p=0,023)$. Também observou-se aumento de pontuação para Ansiedade $(p=0,007)$ e Depressão $(p=0,023)$. Conclusão: As atividades clown podem trazer resultados positivos para a qualidade de vida e suporte social de pacientes elegíveis para $\mathrm{CP}$ em domicílio. Devem ser incentivadas para interagir com o saber das famílias e potencializar o cuidado humanizado, integral e centrado das relações humanas na APS.

Descritores: Cuidados Paliativos; Atenção Primária à Saúde; Terapia do Riso; Qualidade de Vida; Psicometria.

\section{RESUMEN}

Objetivo: Evaluar efectos de actividades clown en calidad de vida, depresión, estrés, ansiedad, apoyo y soporte social en pacientes elegibles para cuidados paliativos (CP) atendidos en Atención Primaria de Salud (APS). Método: Estudio cuasi-experimental, con evaluación preintervención y posintervención, realizado con 16 pacientes elegibles para CP precoces en la APS en municipio del medio oeste. Pacientes recibieron 24 visitas con actividades clown domiciliarias. Resultados: Intervenciones evidenciaron mejora de la calidad de vida y del suporte social, con resultados significativos para la dimensión Actividades Sociales $(p=0,023)$. También se observó aumento de puntuación para Ansiedad $(p=0,007)$ y Depresión $(p=0,023)$. Conclusión: Actividades clown pueden traer resultados positivos a la calidad de vida y suporte social de pacientes elegibles para $\mathrm{CP}$ en domicilio. Deben ser incentivadas para interaccionar con el saber familiar y potencializar el cuidado humanizado, integral y centrado de las relaciones humanas en la APS.

Descriptores: Cuidados Paliativos; Atención Primaria de Salud; Risaterapia; Calidad de Vida; Psicometría. 


\section{INTRODUCTION}

Clown therapy is a flexible approach that adapts to changing conditions and circumstances imposed by disease, pain, alienation, and anguish since the clown can see things from another perspective ${ }^{(1)}$. Its practice has been identified since the time of Hippocrates since physicians of that era believed that humor produced positive effects on health; and introduced into the medical environment by the renowned Hunter Adams (Patch), who stressed that love and humor are fundamental characteristics of this scenario ${ }^{(2-3)}$.

Considering the decline in health status, pain, and loss of hope when faced with the diagnosis of a life-limiting disease and the need for palliative care (PC), this type of therapy becomes relevant. PC configure as a therapeutic possibility by addressing the human being's biopsychosocial and spiritual dimensions, aiming to improve the quality of life of patients and their families in a multi-professional and interdisciplinary way ${ }^{(4-5)}$.

In this context, clown therapy enables patients to make imaginative and intelligent reflections and associations about their living conditions, helping them cope with everyday problems $s^{(1)}$.

Several nomenclatures for therapies use clowns specifically trained to act in health environments, especially hospitals: therapeutic clown, clown therapy, clown care, or juxtaposing words from different languages like English and Portuguese, such as "clownterapia" and "arte clown." The present study adopted the terminology "clown activities", to differentiate the activities of circus clowns from those who perform in other scenic spaces for specific audiences, as in the case of health care and community service environments( ${ }^{(6)}$.

Clown activities consist of programs and activities that involve trained clowns visiting patients in different settings ${ }^{(1,3)}$. The visits generally encompass circus skills, tricks, and improvisation ${ }^{(3)}$. In studies with experimental designs, the frequency of visits varies from once to twice a week in sessions lasting from ten minutes to three hours ${ }^{(6)}$. Most experiences related to this type of activity are described in the hospital setting and with pediatric population ${ }^{(7)}$. No quantitative intervention studies were identified with adult or older individuals in the context of Primary Health Care (PHC).

Since the public policy of $\mathrm{PHC}$ in Brazil provides for the construction of citizenship spaces and health promotion actions, clown activities provide new contours in the obviousness of families' daily lives in situations of social vulnerability. An experience report of home visits conducted by clowns for eight months to ten families belonging to the coverage area of two PHC teams showed that the visits provided the construction of robust and free bonds with the families and enhanced the humanized and comprehensive care, besides helping the family to deal with everyday situations $\mathbf{s}^{(1)}$. Another study ${ }^{(7)}$, carried out with patients with some type of dementia, in long-stay institutions for the elderly (LSIE) in four cities in southern Sweden, showed as benefits of this type of therapy the stimulation of social interactions, better coping with the disease, a better immune response, increased pain tolerance and decreased aggressive and depressive behavior.

Considering that $\mathrm{PC}$ involve health care not only for the patient but also for the family ${ }^{(4-5)}$, the use of humor and laughter in the context of PHC may be a strategy to improve the relationship between patients in $\mathrm{PC}$ and their families, as well as to strengthen the bond between patients and healthcare professionals ${ }^{(8)}$.
Moreover, an experience report ${ }^{(1)}$ of clown interventions performed with adults in a home environment, presenting different health conditions and including conditions eligible for PC, identified improvement in indicators in the participants' statements, such as the performance of activities of daily living, even with physical limitations; decrease in feelings of loneliness; expansion of leisure activities; rescue of old hobbies and acquisition of new ones; and improvement in family dynamics, especially the ability to dialogue and self-care.

Therefore, studies demonstrating the effects of this type of therapy in adult patients eligible for $\mathrm{PC}$ in the PHC context are relevant.

\section{OBJECTIVE}

To evaluate the effects of clown activities on quality of life, depression, stress, anxiety, collective, and social support in eligible patients for PC attended in PHC.

\section{METHOD}

\section{Ethical aspects}

Study approved by the Ethics and Research in Human Beings Committee. All participants signed the Informed Consent Form (ICF) in two copies, being informed about the research objectives, risks, benefits, and method adopted. The use of the scales was made by requesting the authors who initially validated them and those who adapted them for the Brazilian context.

\section{Design and place of study}

That is a quasi-experimental study, with pre-intervention and post-intervention evaluation of a single group. It was conducted with patients eligible for early PC in the PHC of Três Lagoas-MS, Brazil. The study employed clown activities as an intervention and observed its effect on the quality of life, depression, stress, anxiety, collective, and social support related to eligible patients for PC.

\section{Sample and criteria of inclusion/exclusion}

The study universe comprised patients attended at two units of the Family Health Strategy (FHS). The criterion for choosing the research fields was based on the largest number of patients eligible for PC, according to the World Health Organization (WHO) criteria $(\mathrm{WHO})^{(9)}$, followed by the FHS team in the area covered by the unit.

The inclusion criteria were: over 18 years of age, having the cognitive and psychological capacity for participation and eligibility for PC according to the WHO criteria and having at least an early indication for $\mathrm{PC}(\mathrm{KPS}<70 \%)$ based on the data collected in the medical records.

The eligibility criteria proposed by the WHO referred to patients who had one or more of the following pathologies or conditions: Alzheimer's disease and other dementias, cancer, cardiovascular disease (excluding sudden death), liver cirrhosis, congenital anomalies, meningitis, hematological and immunological diseases, neonatal conditions, chronic obstructive pulmonary disease (COPD), diabetes, acquired human immunodeficiency syndrome (HIV/AIDS), renal failure, multiple sclerosis, Parkinson's disease, rheumatoid arthritis, and resistant tuberculosis ${ }^{(9)}$. 
The identification of participants occurred initially by completing a list by Community Health Agents (CHAs), who indicated the patients who met the eligibility conditions mentioned above. All eligible patients'medical records were consulted; and, for those with sufficient data it was applied the Karnofsky Performance Scale (KPS) ${ }^{(10)}$. It was excluded the medical records with insufficient information and those with denied access due to confidential information. The KPS scale was applied considering the records in medical records of complaints, signs, and symptoms referred and capacity for self-care and daily activities. The scale has been used to measure people's functional capacity affected by any pathology. It can also help to formulate the prognosis of patients with chronic disease. Users with performance values below $70 \%$ have an early indication for assistance in $\mathrm{PC}$, and performance of $50 \%$ or less indicates exclusive or end-of-life care, reaffirming that these are eligible for exclusive $P C^{(10)}$. After applying the KPS, a group of 19 participants was delimited, who received home visits with clown activities for three months.

The following criteria were considered for discontinuity of participants in the interventions: participation lower than $80 \%$ in the visits made, hospitalization during the period of data collection, change of address, and worsening of the clinical condition that made it impossible to develop the intervention. Two patients gave up participating in the activities, and one died, totaling a final number of 16 patients.

\section{Study protocol}

All 16 individuals answered the gathering instruments before and after the clown activities in the first and third months of intervention. The characterization instrument was applied only once before the first month of intervention. The intervention with clown activities was based on the implementation of playful and theater activities by students from the Medicine and Nursing courses, who dressed as clowns, with distinctive characters, makeup, and props, in sessions of up to two hours, twice a week, from September to November 2018, in a total of 24 visits for each participant.

The students received theatrical training by participating in workshops guided by actors skilled in clown art. They applied the activities wearing clown costumes provided by the project, baggy pants, colorful shirts, and red noses, and performed actively in shared spaces and individual rooms of the household. The interventions consisted of individual or group conversations, using music, theater, poetry, and storytelling.

Since the beginning of the activities, the family health team professionals contributed to the study's development in terms of identifying patients eligible for $\mathrm{PC}$, according to the research inclusion criteria. The Community Health Agents' (CHAs) participation was essential for introducing the research team to the participants' home care environment. During the clowns' visits to specific patients, a nursing technician, a nurse, a dentist, a physician, and two Community Health Agents participated.

The participants were characterized as sociodemographic variables (gender, age, marital status, religious practice, education, and self-reported pathologies). The Katz Index was also applied, which evaluates the performance in basic activities of daily living (BADL), regarding feeding, sphincters control, transferring, personal hygiene, dressing, and bathing. The answers range from 0 (independent in all six functions) to 6 (dependent in all six functions) $)^{(11)}$.

The study asked two questions to assess the quality of life, depression, stress, anxiety, collective, and social support: "With how many relatives do you feel at ease and can talk about almost anything?" and "With how many friends do you feel at ease and can talk about almost anything?" It was used the following instruments validated and adapted in Brazil or into Portuguese:

- Palliative Care Outcome Scale (POS) - This is a PC outcome scale for the multidimensional evaluation of the quality of life of people with chronic diseases beyond the possibility of cure, covering aspects related to physical symptoms, psychological, spiritual considerations, practical and psychosocial concerns, both personal and family. The total score of the POS is given by the sum of the points of the first ten questions and can range from 0 to 40 points, with higher scores indicating more significant impairment to the person in treatment ${ }^{(12)}$.

- Depression, Anxiety and Stress Scales (DASS 21) - Comprises the evaluation of the depression, anxiety, and stress subscales. Responses are 4 point Likert scale ranging from 0 (did not apply at all) to 3 (applied a lot or most of the time). For each subscale, the possible score ranges from 0 to 21: the higher, the worse is the performance ${ }^{(13)}$.

- Medical Outcomes Study (MOS) - Instrument used to assess the level of social support received, broken down into five dimensions: material (four questions) - provision of practical resources and material help; affective (three questions) - physical displays of love and affection; positive social interaction (four questions) - having people with whom to relax and have fun; emotional (four questions) - the ability of the social network to meet individual needs regarding emotional problems, for example, situations requiring secrecy and encouragement at difficult times in life; and information (four questions) - having people who advise, inform and guide. The answers were presented on a 5 point Likert scale ranging from 1 (never) to 5 (always). For each domain, the possible score is from 0 to 100: the higher, the better the social support received in that domain ${ }^{(14)}$. For the analyses, it was used the model with four factors, which revealed a better quality of adjustment, grouping material support and information dimensions in a single dimension ${ }^{(15)}$.

- Satisfaction with Social Support Scale (SSSS) - Consists of 15 statements that aim to assess social support in the health context, distributed into four factors: friendships, intimacy, family, and social activity. The interviewee must mark the degree to which he/she agrees with the statement (if it applies to him/her) on a 5 point Likert scale, ranging from "strongly agree" to "strongly disagree."The results for each dimension are converted on a scale of 0 to 100 . The higher the score, the better the satisfaction with social support ${ }^{(16)}$.

\section{Data analysis and statistics}

Data were analyzed using the Statistical Package for the Social Sciences (SPSS), version 21.0. Descriptive analysis was performed for categorical variables (absolute and relative frequency tables) and quantitative (central tendency and variability measures). For comparison of instrument scores before and after the clown intervention, it was used the Student's $t$-test for paired samples. Values of $p \leq 0.05$ were considered significant. 


\section{RESULTS}

Among the 16 eligible patients for $\mathrm{PC}$ who received the clown activity intervention, 9 (56.3\%) patients were male, with a mean age of $73.0( \pm 11.1)$ years. Regarding marital status, eight $(50.0 \%)$ were married, six (37.5\%) were widowed, and two (12.5) were divorced. Education: eight (50.0\%) participants had elementary school education, four (25.0\%) were illiterate, three had (18.8\%) higher education, and one (6.3\%) did not answer. Religious practice: five (31.3\%) were Catholic, followed by five Evangelical (31.3\%), and three (18.8\%) had no religion and did not answer, respectively.

Among the self-reported pathologies, the non-transmissible chronic diseases "systemic arterial hypertension (SAH)" and "diabetes mellitus (DM)" were mentioned by all participants. Next were mentioned neurological diseases, stroke, and Alzheimer's disease (25\%), osteoarticular diseases (osteoporosis, arthrosis, and fibromyalgia - 18.75\%), cardiovascular diseases (acute myocardial infarction and vascular - 12.5\%), breast and prostate cancers (12.5\%), eye diseases such as cataract and keratoconus (12.5\%) and chronic renal failure and depression (6.25\% each).

At the pre-intervention evaluation, all participants (100\%) had eligibility for early PC (KPS $<70 \%$ ), according to the inclusion criteria, with $62.5 \%$ having KPS $=70 \%$ and $37.5 \% \mathrm{KPS}=60 \%$. The percentage of participants eligible for early PC decreased to $87.5 \%$ in the post-intervention because two participants became eligible for exclusive PC with KPS $<50 \%$. These differences were not statistically relevant $(p=0.270)$.

In the performance of Basic activities in daily life (BADL), four patients who were previously dependent scored 0 (independent) after the intervention. It also increased the number of dependent participants in four BADLs, where before there was only one; after, two - but with no significant differences $(p=0.564)$.

Table 1 - Evaluation of collective and social support level, quality of life, depression, anxiety, and stress of patients eligible for palliative care before and after the intervention $(N=16)$, Três Lagoas, Mato Grosso do Sul, Brazil, 2019

\begin{tabular}{|c|c|c|c|c|c|}
\hline & \multicolumn{2}{|c|}{ Pre-intervention } & \multicolumn{2}{|c|}{ Post-intervention } & \multirow[b]{2}{*}{$p$} \\
\hline & Medium & $\begin{array}{l}\text { Standard } \\
\text { deviation }\end{array}$ & Medium & $\begin{array}{l}\text { Standard } \\
\text { deviation }\end{array}$ & \\
\hline POS-Br & 14.1 & 4.7 & 10.4 & 7.8 & 0.077 \\
\hline $\begin{array}{l}\text { DASS } \\
\text { Stress } \\
\text { Anxiety } \\
\text { Depression }\end{array}$ & $\begin{array}{l}3.7 \\
1.2 \\
1.9\end{array}$ & $\begin{array}{l}2.3 \\
2.6 \\
3.1\end{array}$ & $\begin{array}{l}4.0 \\
4.6 \\
5.6\end{array}$ & $\begin{array}{l}5.6 \\
5.8 \\
7.2\end{array}$ & $\begin{array}{l}0.800 \\
0.007 \\
0.023\end{array}$ \\
\hline $\begin{array}{l}\text { MOS } \\
\text { Material } \\
\text { Emotional/Information } \\
\text { Interaction } \\
\text { Affective }\end{array}$ & $\begin{array}{l}89.7 \\
84.2 \\
68.1 \\
88.3\end{array}$ & $\begin{array}{l}19.4 \\
15.9 \\
13.5 \\
16.6\end{array}$ & $\begin{array}{l}81.6 \\
80.3 \\
65.3 \\
85.0\end{array}$ & $\begin{array}{l}21.6 \\
18.1 \\
19.1 \\
18.9\end{array}$ & $\begin{array}{l}0.052 \\
0.516 \\
0.431 \\
0.499\end{array}$ \\
\hline $\begin{array}{l}\text { SSSS } \\
\text { Friendships } \\
\text { Intimacy } \\
\text { Family } \\
\text { Social Activity }\end{array}$ & $\begin{array}{l}42.5 \\
51.6 \\
31.2 \\
46.7\end{array}$ & $\begin{array}{l}14.6 \\
15.8 \\
21.2 \\
19.0\end{array}$ & $\begin{array}{l}44.5 \\
54.6 \\
41.2 \\
62.5\end{array}$ & $\begin{array}{l}19.0 \\
15.2 \\
30.1 \\
21.5\end{array}$ & $\begin{array}{l}0.674 \\
0.538 \\
0.100 \\
0.002\end{array}$ \\
\hline $\begin{array}{l}\text { Number of relatives with whom they feel } \\
\text { comfortable and can talk about almost anything }\end{array}$ & 3.7 & 2.9 & 4.3 & 3.9 & 0.470 \\
\hline $\begin{array}{l}\text { Number of friends with whom they feel } \\
\text { comfortable and can talk about almost anything }\end{array}$ & 2.0 & 1.7 & 2.7 & 3.5 & 0.401 \\
\hline
\end{tabular}

Escala de Satisfação com o Suporte Social.
The results of the evaluations of the quality of life, depression, anxiety, stress, and collective and social support, before and after the intervention, can be observed in Table 1.

The quality of life evaluation showed an improvement (with a reduction in the mean score from 14.1 to 10.4), with no significant difference ( $p=0.077)$. For depression, anxiety, and stress, it was possible to observe significant results for anxiety $(p=0.007)$ and depression ( $p=0.023)$, which increased after the intervention.

Concerning social support, pre-intervention, the dimension of support with the highest mean, i.e., the most support received, was the material dimension, followed by the emotional dimension. In the post-intervention, more support was found in the affective dimension, followed by the emotional dimension. Although it was observed a reduction in the support received in all dimensions evaluated before and after the intervention, the results were not significant. The number of relatives and friends with whom the patient felt comfortable talking about almost everything increased when compared before and after the intervention (not significant). In the evaluation of social support, we noticed an increase in the mean score for all dimensions, being significant $(p=0.002)$ for the domain of social activities.

\section{DISCUSSION}

The sample characteristics follow previous studies ${ }^{(17-20)}$, which demonstrated that most PC patients are older people. Regarding gender, the literature ${ }^{(17-18,21-22)}$ shows a prevalence of female patients eligible for PC. However, other studies ${ }^{(19-20)}$ identified a higher percentage of eligible male patients. Investigations ${ }^{(17-21)}$ also confirm that most eligible patients have low education.

There were identified differences concerning the sample's age, and results of a systematic literature review demonstrated that clown interventions could reduce anxiety levels in hospitalized children $^{(23)}$. Not all patients benefit equally from this technique since some do not want to be involved in a humorous and entertaining interaction, so one should look for signs of refusal and attend to this demand ${ }^{(24)}$. It has been observed that in older people, even for those living with dementia in residential care facilities, humor interventions promote positive results, as they provide the meeting of a series of needs, including activity, communication, pleasure, and sociable involvement ${ }^{(25-26)}$.

The most frequent self-reported diseases were High Blood Pressure (HBP) and Diabetes Mellitus (DM), followed by neurological diseases, including cerebrovascular accident (stroke) and Alzheimer's disease. A study carried out in six European countries $^{(18)}$ also showed such data, except in England, where oncological 
diseases were more prevalent. In Japan, $37 \%$ of deaths from conditions requiring PC in 2016 were due to malignant neoplasms, and $31 \%$ were due to heart diseases, including cerebrovascular disease ${ }^{(19)}$.

The eligibility for PC, assessed by KPS, showed that patients worsened in the evaluation, and two were classified as eligible for exclusive PC after the intervention. Worsening performance on the KPS is associated with poor survival in patients eligible for PC, which is a common and expected outcome. In a study of $100 \mathrm{PHC}$ cancer patients, during the 6-month observation period, 55 patients died, three were referred to a hospice and were no longer cared for by their family physician, and 42 survived the observation period $^{(27)}$.

The results showed improvement in the post-intervention quality of life evaluation, with non-significant data. Approaches based on the arts are achieving prominence for their behavioral improvements and promoting older people's quality of life ${ }^{(26)}$. It is known that when there is therapeutic intentionality, the use of humor in end-of-life conditions can improve the quality of life for patients and their families by preserving the dignity of the human being, producing relaxation, helping in pain reduction, and managing other symptoms ${ }^{(8)}$. A study evaluated the quality of life in a sample of $100 \mathrm{PHC}$ patients with cancer and identified a general improvement, even with physical functioning deterioration. Such results highlight the relevance of $P C$ in this level of care and the need for studies that evaluate the effects of humor and laughter in improving the quality of life of these patients ${ }^{(27)}$.

A relevant data is that most participants after the intervention had worsened in the variables Anxiety and Depression. This result may be related to the evolution of patients eligible for PC since it is known that there is a tendency of decline in the KPS over time ${ }^{(28)}$, which may cause damage to mental health. Depression is a common condition in the outpatient setting and causes suffering to the patient and family. The importance of preparing PHC professionals in the early assessment and management of depressive and anxious symptoms of patients in PC is highlighted because these professionals are often the first to be contacted to handle the baseline symptoms. Besides, symptom assessment in PHC enables early referral to specialized professionals and services and continuity of patient care ${ }^{(29)}$.

Such worsening may be related to the higher percentage of men in the sample since studies state that men suffer more from serious and chronic health conditions than women and most often die earlier than women ${ }^{(30)}$. A study with a participatory, qualitative design conducted with men with penile cancer demonstrated that humor helped participants alleviate their situation. However, they were afraid that they would be ridiculed because of their condition ("fear of ridicule")(31). Furthermore, a study aiming to explore the importance and acceptability of humor for patients in PC evidenced that gender was significantly correlated with the acceptability of humor, with men perceiving laughter as inappropriate or neutral ${ }^{(20)}$.

As for the Depression variable, although the present research showed worsening, a study ${ }^{(32)}$ of clown intervention performed with older patients in a Long-stay institution for the elderly (LSIE) in Brazil demonstrate that humor therapy was beneficial from the point of view of non-progression of depression among institutionalized elderly. Another experimental study aimed to evaluate the effects of a humor therapy group in older patients with depressive symptoms identified that the therapy led to lower levels of severity and higher satisfaction with life scores than the control group ${ }^{(33)}$. In PHC, it is known that early integration of PC could impact reducing depression rates since, employing the Anticipatory Care Planning (APC), PHC professionals could help patients and families face the disease make decisions about future treatments. Such an early approach is associated with lower rates of depression in $\mathrm{PC}^{(34)}$.

Regarding the worsening of anxiety identified in this study, we emphasize that the intervention itself may have contributed to these results since being in the patients' homes twice a week may have generated anxiety, which kept them waiting for visits. Anxiety is also associated with daily life stress. Muscle pain, tension-type headache, or hypertension cause chronic anxieties in PC eligible patients' daily lives. It is known that pain and anxiety are the most recurrent stress response symptoms in $P C^{(35)}$. The Anticipatory Care Planning (APC) approach in the PHC context may also influence the reduction of anxiety levels since uncertainties regarding future therapies, and other complex decisions generate feelings of anguish in palliative care patients ${ }^{(34)}$.

In the evaluation of social support, we noticed an increase in the mean score for all dimensions, being significant for the domain of social activities. The mean scores of the number of relatives and friends with whom the patient felt comfortable to talk about almost everything increased when compared before and after the intervention (not significant). Thus, the interaction provided during visits may have increased the patients' perception of social activities. After 12 months of starting an activity program focused on involvement, mood, and behavior of palliative care patients in the home care, there was a significant increase in self or family involvement ${ }^{(36)}$. A systematic review study showed the use of humor in PC as a tool highly capable of decreasing interpersonal distances, improving patient-family-healthcare professionals relationships and among the healthcare team itself, thus culminating in the strengthening and consolidation of therapeutic relationships ${ }^{(8)}$.

Collective support is associated with a better quality of life and reduced anxiety and depression in palliative care patients. Home visits have been identified as an important tool to improve social support, but opportunities to leave the house and engage with others are also considered beneficial for well-being by alleviating physical and psychosocial isolation ${ }^{(37)}$. Therefore, home visits made by clowns to patients eligible for PC in the context of $\mathrm{PHC}$ may have contributed to the improvement in the domain of social activities.

A systematic review(38) revealed that there is still little research available on the use of humor interventions and evaluations in PC and that the few existing intervention studies were conducted with small samples, and that further research is needed to build a solid empirical basis for implementing humor and laughter as part of regular PC activities. A study ${ }^{(39)}$ conducted in Canada attempted to evaluate the effect of clown therapy on Behavioral and Psychological Symptoms of Dementia (BPSD) and quality of life in elderly nursing home residents. A clown duo visited all residents twice a week (approximately ten minutes per visit) for 12 weeks, using improvisation, 
humor, empathy, and expressive modalities such as music, musical instruments, and dance to individualize resident engagement. The pilot study results demonstrated a significant reduction in BPSD and agitation/aggression domain scores in residents with dementia. Another study ${ }^{(7)}$ conducted in four cities in southern Sweden to identify interaction strategies employed by medical clowns in culturally diverse dementia care settings, focusing on ethnographic approach, identified that the clowns took care to "tune in" to the person they were interacting with and be attentive to individual personalities and life stories. The clowns created an attachment and social bond in the relationship using sensory triggers, encouragement, confirmation, and paying attention to places and habits in the past in personalized one-on-one interaction.

However, no studies on the implementation of clown therapy in $\mathrm{PHC}$ have been identified, and the present research is unprecedented and innovative. Such therapy, through the simplicity of the clown, can identify new logics of care in complex daily relationships, enabling the application of soft technologies and the connection with the creative capacity to solve problems and improve social interactions in the context of $\mathrm{PC}$ in $\mathrm{PHC}^{(1)}$.

\section{Study limitations}

The absence of a control group for the comparison of intergroup data and the small sample of 16 participants limit the results'scope. Still, it is worth saying that, because it is a population with vulnerabilities inherent to their own health condition, data evaluation and interpretation become difficult. It may also have influenced the study results that patients eligible for $P C$ have different diagnoses and are inserted in different housing contexts, which may or may not encourage the development of their autonomy, independence, expression of emotions, and socialization.

Moreover, the development of clown activities in PC and the home setting is still recent in Brazil, reflecting the lack of studies and standardized protocols to perform these activities. Being at the patient's home is a challenge because it is the place of intimacy, which required a different approach.

\section{Contributions to the fields of Nursing, Health or Public Policy}

This study's results can subsidize the planning of actions aimed at humanization and integrality in health care, enabling the formation of spaces for citizenship and health promotion consistent with the National Policy of Primary Care and the National
Humanization Policy. They will also contribute to improvements in the PHC health team's performance, envisioning lightweight technologies and creativity to help in problem-solving and interaction with the families' knowledge. Therefore, there will be the possibility of meeting the individualized and immediate needs expressed by patients and families and constituting strong and free bonds, aiming to respond effectively to the complex health demands of individuals and populations and transform environments. Moreover, they will contribute to the increase of records of experiences of clown performance in primary level health care with individuals with chronic conditions eligible for PC.

The healthcare team and the patient's family may not be prepared for home care since some evaluated variables could have improved or maintained after the intervention (e.g., the collective support received, which worsened in all domains). So, the training of $\mathrm{PHC}$ professionals and caregiver support programs should also be encouraged. We highlight the importance of medical and nursing students' participation in extension projects aimed at developing clown activities, meeting the propositions of the National Curriculum Guidelines (NCG) for health courses, which provide for the training of humanistic, critical, and reflective professionals.

\section{CONCLUSION}

The development of clown activities in patients eligible for PC in PHC showed a significant improvement in the domain of social activities in the social support scale. Considering that these patients are dependent and spend most of the time at home, an increase in this domain is an achievement. We noticed a worsening of depressive and anxious symptoms in these patients after the intervention, which can be attributed to their own health condition and the effects of the end of the interventions.

Clown activities in the home environment should be encouraged, and public policies that subsidize them. New studies should be developed to disseminate and standardize these activities when performed at the patients' homes.

\section{FUNDING}

The study was funded by the Coordination for the Improvement of Higher Education Personnel - Brazil (CAPES) - Funding Code 001, the National Council for Scientific and Technological Development (CNPq) - Scientific Initiation Scholarship of Federal University of Mato Grosso do Sul.

\section{REFERENCES}

1. Brito CMD, Silveira R, Mendonça DB, Joaquim RHVT. Humor and laughter in health promotion: a clown insertion experience in the family health strategy. Ciênc Saúde Colet. 2016;21(2):553-62. https://doi.org/10.1590/1413-81232015212.00982015

2. Boscarelli A. Clown therapy: not only a pediatric matter. Transl Pediatr. 2017;6(2):111-2. https://doi.org/10.21037/tp.2017.03.03

3. Dionigi A, Canestrari C. Clowning in Health Settings: the point of view of adults. Eur J Psychol. 2016;12(3):473-88. https://doi.org/10.5964/ ejop.v12i3.1107

4. Gomes ALZ, Othero MB. Cuidados paliativos. Estud Av. 2016;30(88):155-66. https://doi.org/10.1590/s0103-40142016.30880011

5. Gray-Renfrew A, Kimbell B, Finucane A. Emotional experience of people with advanced liver disease: secondary data analysis. Chronic IIIn. 2018;1742395318803668. https://doi.org/10.1177/1742395318803668 
6. Catapan SC, Oliveira WF, Rotta TM. Palhaçoterapia em ambiente hospitalar: uma revisão de literatura. Ciênc Saúde Colet. 2019;24(9):3417-29. https://doi.org/10.1590/1413-81232018249.22832017

7. Rämgård M, Carlson E, Mangrio E. Strategies for diversity: medical clowns in dementia care - an ethnographic study. BMC Geriatr. 2016;16(1):152. https://doi.org/10.1186/s12877-016-0325-z

8. Pinna MÁC, Mahtani-Chugani V, Sánchez Correas MÁ, Sanz Rubiales A. The use of humor in palliative care: a systematic literature review. Am J Hosp Palliat Care. 2018;35(10):1342-54. https://doi.org/10.1177/1049909118764414

9. World Health Organization (WHO). How many people at the end of life are in need of palliative care worldwide? In: Worldwide Palliative Care Alliance (WPCA). Global Atlas of Palliative Care at the end of life [Internet]. Londres: WPCA; 2014 [cited 2019 Sep 15]. Available from: http://www.thewhpca.org/resources/global-atlas-on-end-of-life-care

10. Péus D, Newcomb N, Hofer S. Appraisal of the Karnofsky Performance Status and proposal of a simple algorithmic system for its evaluation. BMC Med Inform Decis Mak. 2013;13(72):2-7. https://doi.org/10.1186/1472-6947-13-72

11. Lino VTS, Pereira SRM, Camacho LAB, Ribeiro Filho ST, Buksman S. Adaptação transcultural da Escala de Independência em Atividades da Vida Diária (Escala de Katz). Cad Saúde Pública. 2008;24(1):103-12. https://doi.org/10.1590/S0102-311X2008000100010

12. Rugno FC. Validação da versão adaptada para o português do Brasil da Palliative Care Outcome Scale (POS) [Tese]. Ribeirão Preto. Escola de Enfermagem de Ribeirão Preto da Universidade de São Paulo; 2017.

13. Vignola RC, Tucci AM. Adaptation and validation of the Depression, Anxiety and Stress Scale (DASS) to Brazilian portuguese. J Affect Disord. 2014;155:104-9. https://doi.org/10.1016/j.jad.2013.10.031

14. Sherbourne CD, Stewart AL. The MOS social support survey. Soc Sci Med. 1991;32(6):705-14. https://doi.org/10.1016/0277-9536(91)90150-B

15. Zanini DS, Peixoto EM. Social Support Scale (MOS-SSS):Analysis of the psychometric properties via item response theory. Paidéia. 2016;26(65):359-68. https://doi.org/10.1590/1982-43272665201612

16. Ribeiro JLP. Escala de Satisfação com o Suporte Social (ESSS). An Psicol [Internet]. 1999 [cited 2019 Sep 15];17(3):547-58. Available from: http://www.scielo.mec.pt/pdf/aps/v17n3/v17n3a10.pdf

17. Bastos BR, Pereira AKS, Castro CC, Carvalho MMC. Perfil sociodemográfico dos pacientes em cuidados paliativos em um hospital de referência em oncologia do estado do Pará, Brasil. Rev Pan-Amaz Saude. 2018;9(2):31-6. https://doi.org/10.5123/s2176-62232018000200004

18. Honinx E, van Dop N, Smets T, Deliens L, Van Den Noortgate N, Froggatt K, et al. Dying in long-term care facilities in Europe: the PACE epidemiological study of deceased residents in six countries. BMC Public Health. 2019;19(1):1199. https://doi.org/10.1186/s12889-019-7532-4

19. Nakanishi M, Ogawa A, Nishida A. Availability of home palliative care services and dying at home in conditions needing palliative care: a population-based death certificate study. Palliat Med. 2020;34(4):504-12. https://doi.org/10.1177/0269216319896517

20. Ridley J, Dance D, Pare D. The acceptability of humor between palliative care patients and health care providers. J Palliat Med. 2014;17(4):472-4. https://doi.org/10.1089/jpm.2013.0354

21. Castôr KS, Moura ECR, Pereira EC, Alves DC, Ribeiro TS, Leal PC. Cuidados paliativos: perfil com olhar biopsicossocial dentre pacientes oncológicos. BrJP. 2019;2(1):49-54. https://doi.org/10.5935/2595-0118.20190010

22. Ten Koppel M, Onwuteaka-Philipsen BD, Van den Block L, Deliens L, Gambassi G, Heymans MW, et al. Palliative care provision in long-term care facilities differs across Europe: results of a cross-sectional study in six European countries (PACE). Palliat Med. 2019;33(9):1176-88. https://doi.org/10.1177/0269216319861229

23. Sridharan K, Sivaramakrishnan G. Therapeutic clowns in pediatrics: a systematic review and meta-analysis of randomized controlled trials. Eur J Pediatr. 2016;175(10):1353-60. https://doi.org/10.1007/s00431-016-2764-0

24. Auerbach S. Are Clowns Good for Everyone? the influence of trait cheerfulness on emotional reactions to a hospital clown intervention. Front Psychol. 2017;8:1973. https://doi.org/10.3389/fpsyg.2017.01973

25. Goodenough B, Low LF, Casey AN, Chenoweth L, Fleming R, Spitzer P et al. Study protocol for a randomized controlled trial of humor therapy in residential care: the Sydney Multisite Intervention of LaughterBosses and ElderClowns (SMILE). Int Psychogeriatr. 2012;24(12):2037-44. https://doi.org/10.1017/S1041610212000683

26. Low LF, Brodaty H, Goodenough B, Spitzer P, Bell JP, Fleming R et al. The Sydney Multisite Intervention of LaughterBosses and ElderClowns (SMILE) study: cluster randomised trial of humour therapy in nursing homes. BMJ Open. 2013;3(1):e002072. https://doi.org/10.1136/ bmjopen-2012-002072

27. Krug K, Miksch A, Peters-Klimm F, Engeser P, Szecsenyi J. Correlation between patient quality of life in palliative care and burden of their family caregivers: a prospective observational cohort study. BMC Palliat Care. 2016;15:4. https://doi.org/10.1186/s12904-016-0082-y

28. Tapper EB, Su GL. Does Karnofsky Performance Status of Patients With Cirrhosis on the Transplant Waitlist Meet the Eyeball Test? Clin Gastroenterol Hepatol. 2016;14(8):1196-8. https://doi.org/10.1016/j.cgh.2016.04.024

29. Ghosh A, Dzeng E, Cheng MJ. Interaction of Palliative Care and Primary Care. Clin Geriatr Med. 2015;31(2):207-18. https://doi.org/10.1016/j. cger.2015.01.001

30. Carvalho FPB, Silva SKN, Oliveira LC, Fernandes ACL, Solano LC, Barreto ELF. Conhecimento acerca da política nacional de atenção integral à saúde do homem na estratégia de saúde da família. Rev APS [Internet]. 2013[cited 2019 Sep 15];16(4):386-92. Available from: https:// periodicos.ufjf.br/index.php/aps/article/view/15265 
31. Branney P, Witty K, Braybrook D, Bullen K, White A, Eardley I. Masculinities, humor and care for penile cancer: a qualitative study. J Adv Nurs. 2014;70(9):2051-60. https://doi.org/10.1111/jan.12363

32. Pires WGB, Pessalacia JDR, Mata LCF, Kuznier TP, Panitz GEC. Efeito da intervenção clown no padrão de depressão de idosos em instituição de longa permanência. Cienc Enferm. 2015;21(2):99-111. https://doi.org/10.4067/S0717-95532015000200010

33. Konradt B, Hirsch RD, Jonitz MF, Junglas K. Evaluation of a standardized humor group in a clinical setting: a feasibility study for older patients with depression. Int J Geriatr Psychiatr. 2012;28(8):850-7. https://doi.org/10.1002/gps.3893

34. Buss MK, Rock LK, McCarthy EP. Understanding Palliative Care and Hospice. Mayo Clinic Proceedings. 2017;92(2):280-6. https://doi. org/10.1016/j.mayocp.2016.11.007

35. Satsangi AK, Brugnoli MP. Anxiety and psychosomatic symptoms in palliative care: from neuro-psychobiological response to stress, to symptoms' management with clinical hypnosis and meditative states. Ann Palliat Med. 2018;7(1):75-111. https://doi.org/10.21037/ apm.2017.07.01

36. Low LF, Baker JR, Harrison F, Jeon YH, Haertsch M, Camp C, et al. The Lifestyle Engagement Activity Program (LEAP): implementing social and recreational activity into case-managed home care. J Am Med Dir Assoc. 2015;16(12):1069-76. https://doi.org/10.1016/j.jamda.2015.07.002

37. Bradley N, Lloyd-Williams M, Dowrick C. Effectiveness of palliative care interventions offering social support to people with life-limiting illness: a systematic review. Eur J Cancer Care (Engl). 2018;27(3):e12837. https://doi.org/10.1111/ecc.12837

38. Linge-Dahl LM, Heintz S, Ruch W, Radbruch L. Humor assessment and interventions in palliative care: a systematic review. Front Psychol. 2018;9:890. https://doi.org/10.3389/fpsyg.2018.00890

39. Kontos P, Miller KL, Colobong R, Lazgare LIP, Binns M, Low LF, et al. Elder-Clowning in Long-Term Dementia Care: results of a pilot study. J Am Geriatr Soc. 2016;64(2):347-53. https://doi.org/10.1111/jgs.13941 